TECHNICAL TRANSACTIONS 2/2017

CZASOPISMO TECHNICZNE 2/2017

MECHANICS

DOI: $10.4467 / 2353737$ XCT.17.026.6219

\author{
Karolina Głogowska (k.glogowska@pollub.pl) \\ Janusz W. Sikora \\ Department of Polymer Processing, Faculty of Mechanical Engineering, Lublin \\ University of Technology
}

\title{
THE PRODUCTION AND PROPERTIES OF MICRO-EXTRUDED LOW-DENSITY POLYETHYLENE MICROTUBES
}

OTRZYMYWANIE I WŁAŚCIWOŚCI MIKROWYTŁOCZYN Z POLIETYLENU MAŁEJ GĘSTOŚCI

\begin{abstract}
Micro-extrusion is the process of obtaining microtubes with either simple or complex cross-sections which are used for the high-precision transport and protection of various of media. Through this process, it is possible to create tubing with interior diameters and wall thicknesses as small as $0.1 \mathrm{~mm}$ and $0.05 \mathrm{~mm}$ respectively. Micro-extruded tubing such as micro catheters and peripheral intravenous cannulas are employed in microfluidics, paediatrics and micro-analytics. This article presents the results of granulometric tests of micropellets produced by micro-extrusion with cold pelletizing and results of tensile strength tests of microrods of different diameters. The trials were performed using a standard twin-screw extruder and low-density polyethylene.
\end{abstract}

Keywords: polymer micro-extrusion, low-density polyethylene, micropellets

\section{Streszczenie}

Mikrowytlaczanie to proces wytwarzania mikrorurek prostych lub złożonych w przekroju poprzecznym, używanych do wysoce precyzyjnego przesyłu oraz ochrony różnych mediów. Dzięki temu procesowi możliwe jest uzyskanie rurek o średnicy wewnętrznej i grubości ścianek tak małych jak 0,1 mm i 0,5 mm. Rurki wytłoczone w ten sposób, np. mikrocewniki i kaniule dożylne, stosowane są w technikach mikroprzepływowych, pediatrii i mikroanalizie. Niniejszy artykul przedstawia wyniki testów granulometrycznych mikrogranulek wytworzonych poprzez mikrowytlaczanie z granulowaniem na zimno, jak również testów wytrzymałości na rozciąganie mikrożyłek o różnych średnicach. Próby zostały przeprowadzone przy użyciu standardowej wytlaczarki dwuślimakowej i polietylenu małej gęstości.

Słowa klucze: mikrowytłaczanie polimerów, polietylen małej gęstości, mikrogranulki 


\section{Introduction}

The constant progress of science leads to changes in the developmental of technology. One manifestation of these changes is the introduction of new and improved machinery, equipment, tools and technologies into the production process that can be used to manufacture higher quality products with new, hitherto unknown, functionalities. The polymer processing technology, in which one of the trends is to miniaturise both equipment and products, has not been left unaffected by this development. Examples of miniaturisation include processing procedures, such as micro-injection moulding and micro-extrusion performed using microinjection moulding machines and micro-extruders [1-4].

The process of micro-extrusion can be used to form microrods or microtubes with either simple or complex cross-sectional shapes, and outer diameters and wall thickness as small as $0.2 \mathrm{~mm}$ and $0.05 \mathrm{~mm}$, respectively [5, 6]. These products are mainly applied in medicine, in fields such as vascular surgery, and optics. Poly(vinyl chloride), poly(vinyl acetate) and silicone are used to produce various types of catheters with diameters as small as $2 \mathrm{~mm}[7,8]$; PVC and polyurethane (PUR) are applied in the production of tubing with even smaller diameters $-0.5 \mathrm{~mm}[9]$.

In coronary artery bypass graft surgeries, surgeons use artificial blood vessels called by-passes with diameters of as small as $3 \mathrm{~mm}$, extruded from silicones or PUR [10]. Also common are different kinds of small-diameter (e.g. $0.9 \mathrm{~mm}$ ) capillaries, used for transport, protection and dispensing of various media [11]. Sutures with diameters starting from $0.1 \mathrm{~mm}$ [12] are obtained from many kinds of plastics, such as PP, PVA, PE, PA, and PUR, by using spinnerets [13]. The process of extrusion pelletising is applied in the production of micropellets with diameters ofless than $1 \mathrm{~mm}$ [14] which are readily used in the increasingly popular process of rotational moulding [15] or in the production of modifying concentrates, so-called masterbatches (colour masterbatches, lubricant masterbatches, etc.) [16]. Micropellets can be widely used for the mass-production of nanofiber through bubble electrospinning or bubbfil spinning [17].

The aim of the experiments was to produce microrods using a twin-screw extruder, and to process sections of them into micropellets with the aim of establishing the functional relationship between the diameter of the microrods and their tensile strength, as well as determining the basic granulometric properties of the micropellets, including their natural repose angle and bulk density.

\section{Experimental}

\subsection{Material}

The micro-extrudate and the micropellets obtained from it were produced from a lowdensity polyethylene (LDPE) sold under the trade name Malen E, symbol FABS 23-D022, manufactured by Basell Orlen Polyolefins based in Plock (Poland). The main properties of this 
polymer are presented in Table 1 . This polymer is widely used in the processing industry, mainly in the manufacturing of various types of films (e.g., packaging films and shrink films), as it is highly elastic and weldable.

Table 1. The basic properties of the test polymer, according to the manufacturer's data

\begin{tabular}{|c|c|c|}
\hline Property & Unit & Value \\
\hline Standard density at $23^{\circ} \mathrm{C}$ & {$\left[\mathrm{kg} / \mathrm{m}^{3}\right]$} & $915-920$ \\
Melting point & {$\left[{ }^{\circ} \mathrm{C}\right]$} & $105-118$ \\
Degradation temperature & {$\left[{ }^{\circ} \mathrm{C}\right]$} & 300 \\
Degree of crystallinity & {$[\%]$} & $40-50$ \\
Melt flow rate $(\mathrm{MFR})\left(190^{\circ} \mathrm{C} / 2.16 \mathrm{~kg}\right)$ & {$[\mathrm{g} / 10 \mathrm{~min}]$} & 1.95 \\
Shore hardness & {$\left[{ }^{\circ} \mathrm{Sh} \mathrm{D}\right]$} & 48 \\
Vicat softening temperature A50, $\left(50^{\circ} \mathrm{C} / \mathrm{h} 10 \mathrm{~N}\right)$ & {$\left[{ }^{\circ} \mathrm{C}\right]$} & 91 \\
\hline
\end{tabular}

\subsection{Test stand}

The tests were carried out using an EHP $2 \times 20$ Sline Zamak Mercator twin-screw extruder, intended for use in the extrusion of composite materials based on powder- and fibre-reinforced thermoplastics (Fig. 1). The co-rotating twin screw extruder, which was a component of a technological line, had a system of two volumetric feeders. The extruder was equipped with cylindrical, segmented screws with a length-to-diameter ratio of 40 , and a cross-type head with two circular cross-section dies. The technical specification of the extruder is presented in Table 2. The temperatures of the feed opening zone and each zone of the barrel were regulated with electric heaters and a water jacket cooling system. The plasticizing system of the extruder was more abrasion- and corrosion-resistant due to the use of inserts that were hot-pressed using hot isostatic pressing (HIP) technology.

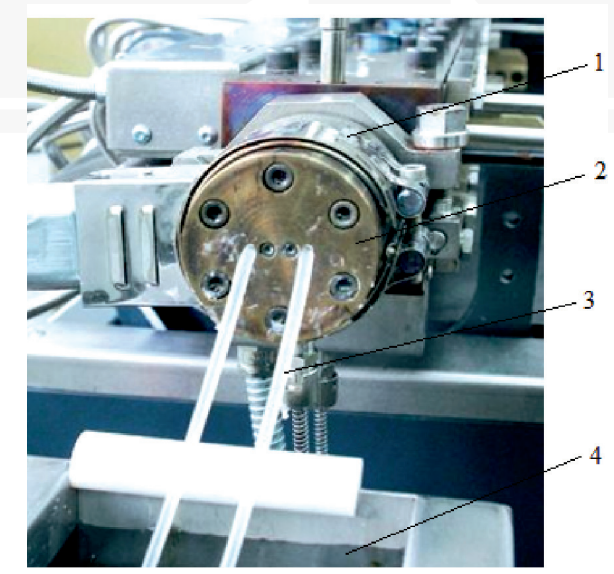

Fig. 1. A cross-type head with two $3 \mathrm{~mm}$-diameter dies: 1 - extrusion head, 2 - heating component, 3 - extrudate, 4 - fragment of cooling bath 
Table 2. Technical specification of the ZAMAK Mercator EHP $2 \times 20$ Sline extruder

\begin{tabular}{|c|c|c|}
\hline Technical details & Unit & Value \\
\hline Number of screws & {$[\mathrm{pcs}]$.} & 2 \\
\hline Screw diameter & {$[\mathrm{mm}]$} & 20 \\
\hline Working length of screws & {$[\mathrm{mm}]$} & $40 \mathrm{D}$ \\
\hline Screw type & - & segmented \\
\hline Barrel type & - & segmented, divided \\
\hline Maximum rotational speed of screws & {$[\mathrm{rpm}]$} & 800 \\
\hline Number of barrel heating zones & {$[\mathrm{pcs}]$.} & 9 \\
\hline Maximum working pressure & {$[\mathrm{MPa}]$} & 20 \\
\hline Maximum working temperature & {$\left[{ }^{\circ} \mathrm{C}\right]$} & 400 \\
\hline
\end{tabular}

Upstream of the cooling bath there was a G-16/32 Zamak Mercator pellet mill with a motor power of $1.66 \mathrm{~kW}$, fitted out with an adjustable-speed puller and a milling cutter with 18 cutting edges, with an outer diameter of $125.25 \mathrm{~mm}$, used for cutting the microrods into single micropellets. Microrod take-off speed and the rotational speed of the cutter were adjusted by a servo drive with a power of $1.6 \mathrm{~kW}$ via a control system. Microrods were passed onto a feed roller and then positioned by a pressure roller that cooperated with a drive roller (Fig. 2) - together, these formed a system of pull-up rollers. This system guided the feeding of the polymer in the direction of the rotating milling cutter and allowed for the simultaneous cutting of up to 4 microrods.

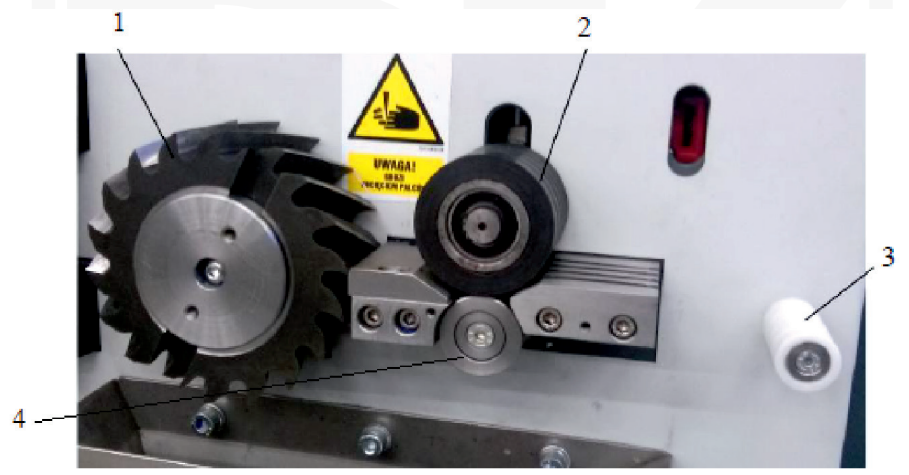

Fig. 2. The pelletizer: 1 - milling cutter, 2 - pressure roller, 3 - feed roller, 4 - drive roller

Tensile tests of the microrods were carried out using a Z010 Zwick/Roell tensile tester (Ulm, Germany). The Z010 machine operates with a maximum tensile load of $10 \mathrm{kN}$ and a tensile speed of up to $2000 \mathrm{~mm} / \mathrm{min}$. The bulk pellet density and the natural repose angle of the micropellets were measured using a hopper with a closing slide, which was mounted and raised to a specific height on a measuring frame. 


\subsection{Test factors}

A list of the most important test factors characterising the studied process was designed for the purposes of tensile and granulometric tests. The following test factors were considered:

Direct output factors:

- microrod diameter, $d$,

- diameter d and length of micropellets, $l$,

- microrod breaking force, $N$.

Indirect output factors:

- bulk density $\beta, \mathrm{kg} / \mathrm{m}^{3}$,

- angle of natural repose of pellets, deg,

- breaking stress $\sigma, \mathrm{MPa}$.

Variable factors:

- microrod take-off speed in the pelletiser V - 6.1, 9.4, 14.6, 20.2, $27.1 \mathrm{~m} / \mathrm{min}$,

- rotational speed of the milling cutter - 80, 145, 195, 210, 335, 360, 600, $705 \mathrm{rpm}$.

Constant factors:

- processed material (LDPE),

- diameter of the extrusion head die $2 \mathrm{~mm}$,

- others geometric elements of the extrusion head die and the plasticising unit,

- temperature in the individual zones of the plasticising system of the extruder (Table 3),

Table 3. The temperatures in the individual heating zones

\begin{tabular}{|c|c|c|}
\hline Extruder component & Zone no. & Pre-set temperature $\left[{ }^{\circ} \mathrm{C}\right]$ \\
\hline Feed opening zone & 1 & 46.5 \\
\hline \multirow{9}{*}{ 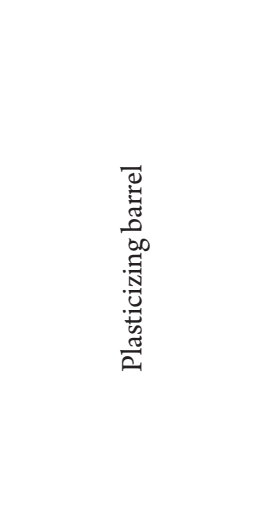 } & 1 & 125 \\
\hline & 2 & 130 \\
\hline & 3 & 140 \\
\hline & 4 & 150 \\
\hline & 5 & 160 \\
\hline & 6 & 160 \\
\hline & 7 & 160 \\
\hline & 8 & 170 \\
\hline & 9 & 170 \\
\hline Connector & 1 & 170 \\
\hline \multirow{2}{*}{ Head } & 1 & 170 \\
\hline & 2 & 170 \\
\hline
\end{tabular}


- polymer pressure in the extrusion head, $0.9 \mathrm{MPa}$;

- rotational speed of screws in the plasticising unit, $20 \mathrm{rpm}$.

Interfering factors:

- voltage, 219-241 V;

- relative air humidity, 55-65\%;

- ambient temperature, $20-24^{\circ} \mathrm{C}$. On the basis of the course of the micro-extrusion process, it was assumed that the impact of the interfering factors was small and could be neglected since those factors did not affect the results.

\subsection{Method}

To produce microrods of different diameters, the microrod take-off speeds in the pelletiser was manipulated. Microrod take-off speed was set on the front touch control panel of the pelletiser; the corresponding microrod diameters are shown in Table 4.

The microrods obtained in this way were measured, described and prepared for strength measuring. They were cut with scissors to the desired lengths (150 to $165 \mathrm{~mm}$ ), so that they could be placed in the grips of the Zwick/RoellZ010 strength testing machine. Tensile tests of the microrods were performed according to the ISO 527-1:2012 standard at a test speed of $100 \mathrm{~mm} / \mathrm{min}$. Bulk density tests were carried out according to the ISO 60:1998 standard. Natural repose tests were prepared in accordance with the guidelines of ISO 6186:2001.

Table 4. The relationship between microrod diameter and take-off speed

\begin{tabular}{|c|c|}
\hline Take-off speed $[\mathrm{m} / \mathrm{min}]$ & Diameter $[\mathrm{mm}]$ \\
\hline 6.1 & 1.45 \\
\hline 9.4 & 1.20 \\
\hline 14.6 & 0.95 \\
\hline 20.2 & 0.80 \\
\hline 27.1 & 0.65 \\
\hline
\end{tabular}

To obtain micropellets of different sizes, we used three microrod take-off speeds in the pelletiser and eight different speeds of the milling cutter (Table 5). The rotational speeds of the milling cutter were different each time as we wanted to obtain micropellets of the same length. Microrods with diameters of $0.8 \mathrm{~mm}$ and $0.65 \mathrm{~mm}$ were not pelletised, due to the milling cutter's inability to pelletize such small rods.

The smallest micropellet diameter obtained was $0.95 \mathrm{~mm}$. As a final outcome, three different micropellet lengths and three different micropellet diameters were obtained giving a total of nine different combinations. Differences in the appearance of the micropellets are shown in photographs in Figures 3 to 5. Both microrods for strength tests and micropellets lengths were obtained at constant extruder setting parameters. The micropellets were dried at $50^{\circ} \mathrm{C}$ for approx. 24 hours. 
Table 5. The relationship between the setting parameters of the Zamak Mercator G-16/32 pelletiser and the geometric dimensions of the pellets

\begin{tabular}{|c|c|c|c|c|}
\hline \multirow{2}{*}{$\begin{array}{l}\text { Specimen } \\
\text { No. }\end{array}$} & \multicolumn{2}{|c|}{ Pellet size } & \multirow{2}{*}{$\begin{array}{l}\text { Take-off speed } \\
{[\mathrm{m} / \mathrm{min}]}\end{array}$} & \multirow{2}{*}{$\begin{array}{c}\text { Rotational speed } \\
\text { of milling cutter }[\mathrm{rpm}]\end{array}$} \\
\hline & Diameter $[\mathrm{mm}]$ & Length $[\mathrm{mm}]$ & & \\
\hline 1 & \multirow{3}{*}{0.95} & 1.0 & \multirow{3}{*}{14.6} & 705 \\
\hline 2 & & 2.4 & & 335 \\
\hline 3 & & 3.8 & & 195 \\
\hline 4 & \multirow{3}{*}{1.20} & 1.0 & \multirow{3}{*}{9.4} & 600 \\
\hline 5 & & 2.4 & & 210 \\
\hline 6 & & 3.8 & & 145 \\
\hline 7 & \multirow{3}{*}{1.45} & 1.0 & \multirow{3}{*}{6.1} & 360 \\
\hline 8 & & 2.4 & & 145 \\
\hline 9 & & 3.8 & & 80 \\
\hline
\end{tabular}

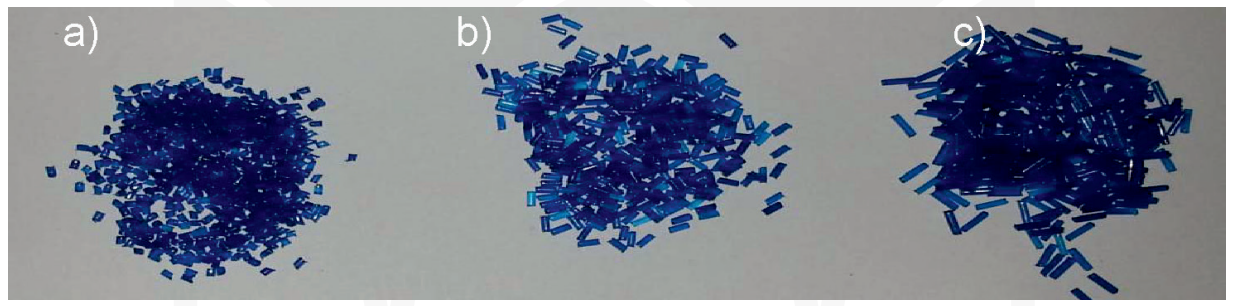

Fig. 3. Pellets with diameter $d=0.95 \mathrm{~mm}$ and length $l:$ a) $1 \mathrm{~mm}, \mathrm{~b}) 2.4 \mathrm{~mm}, \mathrm{c}) 3.8 \mathrm{~mm}$

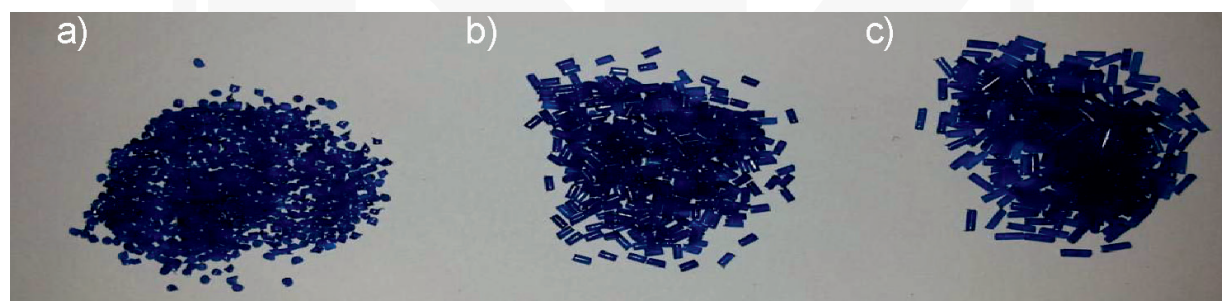

Fig. 4. Pellets with diameter $d=1.20 \mathrm{~mm}$ and length $l:$ a) $1 \mathrm{~mm}$, b) $2.4 \mathrm{~mm}, \mathrm{c}) 3.8 \mathrm{~mm}$

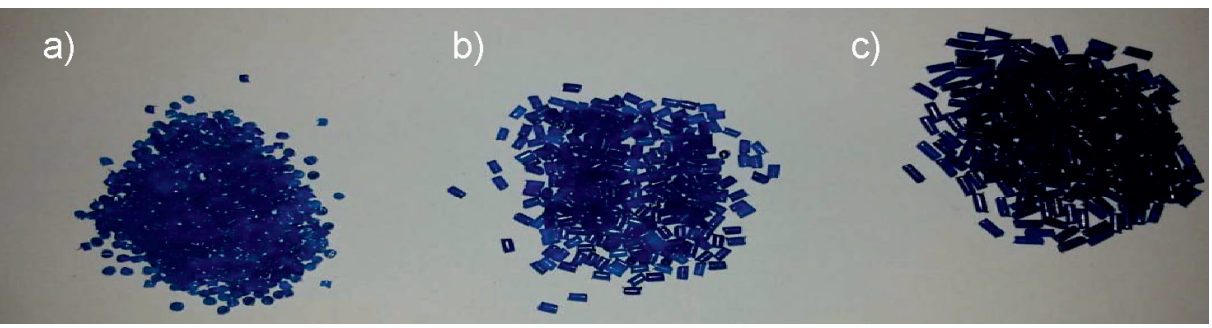

Fig. 5. Pellets with diameter $d=1.45 \mathrm{~mm}$ and length $l:$ a) $1 \mathrm{~mm}$, b) $2.4 \mathrm{~mm}$, c) $3.8 \mathrm{~mm}$ 


\section{Results and discussion}

Based on the results obtained in the experiments, the following graphs were plotted: tensile stress vs. strain for each specimen tested; breaking stress vs. microrod diameter; bulk density and natural repose angle vs. micropellet length at different pellet diameters. Regression equations were formulated where possible. Mathematical models made in this way describe in detail the connections between the studied indirect and direct factors in the accepted range of value changes.

\subsection{Determination of strength parameters}

The values of tensile stress as a function of strain for all tested microrods are shown in graphic form in Figure 6. The graph shows two tensile strength curves for microrods of each given diameter. Maximum tensile stress was equal to tensile stress at break in all cases. The curves of tensile stress as a function of strain did not differ significantly and the values of the test factors were comparable. The graph of tensile stress as a function of strain shows that out of all the microrods tested, those with a diameter of $0.65 \mathrm{~mm}$ showed the lowest strain at $200 \%$, while the microrods with the largest diameter had approx. four times higher strain values. When analysing the results of the studies, it can be clearly concluded that the diameter of microrods has a significant influence on the strength properties of polymer products. This effect is probably caused by higher orientation of polymer chains in objects with a small diameter - a higher microrod take-off speed results in a higher orientation in a take-off direction and consequently increases ultimate tensile strength.

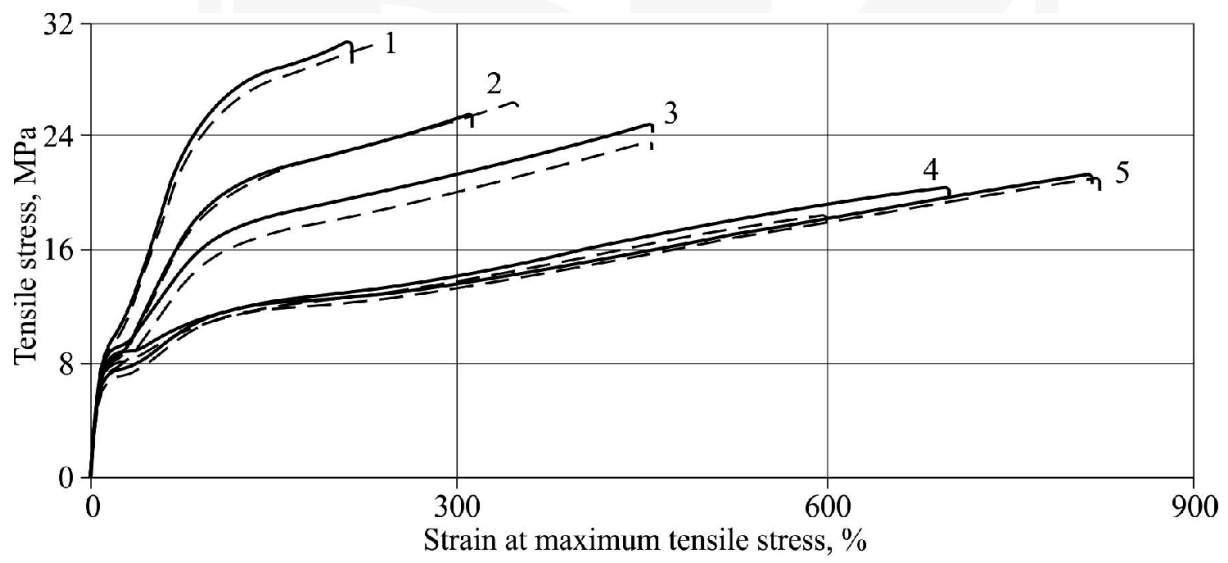

Fig. 6. Graph of stress $\sigma$ vs. strain $\varepsilon$ of test microrods with diameters of: $1-0.65 \mathrm{~mm} ; 2-0.80 \mathrm{~mm} ; 3-0.95 \mathrm{~mm}$; 4-1.20 mm; and 5-1.45 $\mathrm{mm}$

Figure 7 shows a graph of stress needed to break a microrod as a function of microrod diameter. It was observed that along with changing microrod diameter, tensile stress at 
break, and thus maximum tensile stress, increased. The maximum value of tensile stress at break was $30.60 \mathrm{MPa}$ for the diameter of $0.65 \mathrm{~mm}$, and the minimum value was $19.50 \mathrm{MPa}$ for the diameter of $1.20 \mathrm{~mm}$, which represents a $36.27 \%$ decrease. This can be caused by a better packing of chains in the space and a large rapprochement of macroparticles, which results in stronger bonds among the chains and then gives improved mechanical properties of microrods of a smaller diameter.

On the basis of the study results, a computer-aided regression equation was determined this describes the relationship between the tensile stress at break and microrod diameter using the approximation with the method of the smallest squares. The coefficients in the regression equation and the coefficient of correlation $r$ were also determined by means of a computer programme.

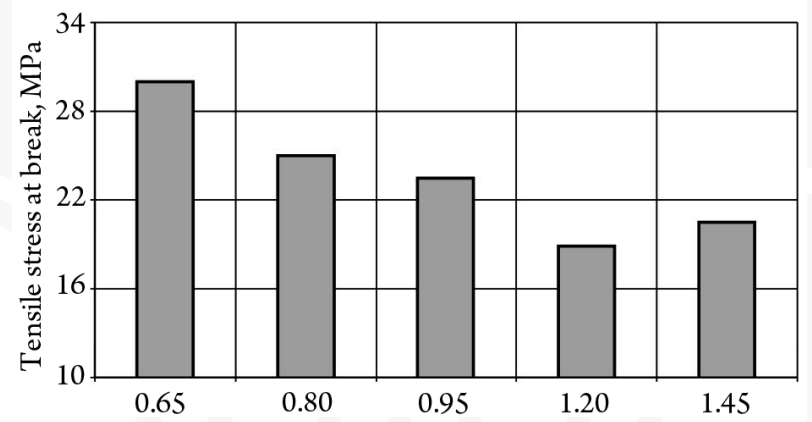

Fig. 7. Relationship between tensile stress at break and microrod diameter

In this case, the regression equation in the form of a second degree polynomial is as follows:

$$
\sigma=61.921 d^{2}-65.829 d+25.589
$$

The coefficient of correlation for this mathematical model is 0.983 , this proves a very strong correlation between the tensile stress at break and the microrod diameter.

\subsection{Granulometric tests}

As before, regression equations describing the relationships between the bulk density and micropellet length (Fig. 8) and between the natural repose angle and micropellet length (Fig. 9) were determined as were the respective coefficients of correlations. The equations are as follows:

a) for micropellets diameter $0.95 \mathrm{~mm}$ :

$\rho=477.143 l^{2}+43.571 l-10.714$; with $r=0.999$;

$\beta=19.975 l^{2}-1.391 l+0,115$; with $r=0.999$;

b) for diameter $1.20 \mathrm{~mm}$ :

$\rho=488.469 l^{2}+40.204 l-8.673$; with $r=0.999$;

$\beta=1.081 l^{2}+0.094 l+1.754$; with $r=0.999$; 


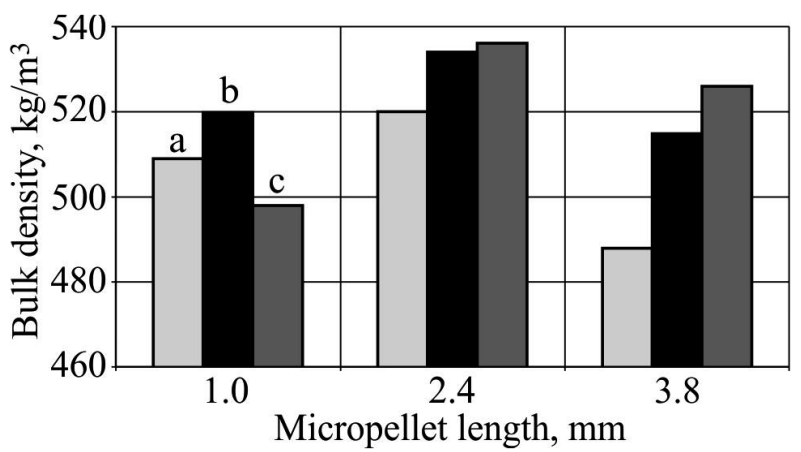

Fig. 8. The relationship between bulk density and micropellet length for different micropellet diameters:

a) $d=0.95 \mathrm{~mm}$, b) $d=1.20 \mathrm{~mm}, \mathrm{c}) d=1.45 \mathrm{~mm}$

c) for diameter $1.45 \mathrm{~mm}$ :

$\rho=438.918 l^{2}+72.092 l-13.010$; with $r=0.998$;

$\beta=18.435 l^{2}-0.773 l+0,038$; with $r=0.999$.

Based on these results, it was found that LDPE micropellets with a diameter of $0.95 \mathrm{~mm}$ and a length of $3.8 \mathrm{~mm}$ had the lowest bulk density of $487.9 \mathrm{~kg} / \mathrm{m}^{3}$. The largest bulk density measured was $536.5 \mathrm{~kg} / \mathrm{m}^{3}$ for micropellets with a diameter of $1.45 \mathrm{~mm}$ and length of $2.4 \mathrm{~mm}$.

The highest density values were recorded for micropellets with an average pellet length of $2.4 \mathrm{~mm}$, and the lowest for the shortest micropellets. The difference between the highest and lowest bulk density of the test micropellets was approx. $10 \%$. The bulk density of polymers depends upon, among other factors, the size and shape of pellets and the method of pellet placement in the hopper. The pellet placement is influenced by many factors: the method of introducing the pellets; height of their introduction; shape and dimensions of the hopper; geometrical features of the pellets [18].

The largest natural repose angle was measured for micropellets with a length of $1 \mathrm{~mm}$ and a diameter of $0.95 \mathrm{~mm}$ (Fig. 9). The differences between the smallest and the largest values of the natural repose angle were slight (approx. 2.6 degrees). Along with the decreasing micropellet length and diameter, the natural angle of repose increased. It can be assumed that this was due to the increase in frictional resistance of the external micropellets.

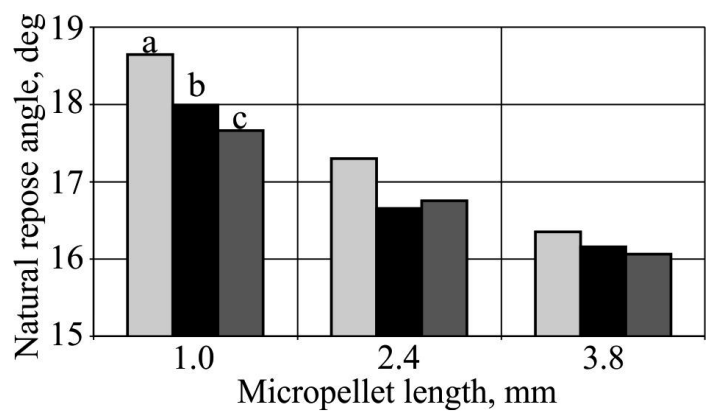

Fig. 9. The relationship between natural repose angle and micropellet length for different micropellet diameters: a) $d=0.95 \mathrm{~mm}, \mathrm{~b}) d=1.20 \mathrm{~mm}, \mathrm{c}) d=1.45 \mathrm{~mm}$ 
The value of the natural angle of repose is also affected by the shape and size of grains, as well as by the mutual mobility of the particles, which depends on the forces of adhesion between the individual particles, as well as the previously mentioned frictional resistance arising from the mutual movement of particles [19].

\section{Conclusions}

The experiments and the analysis of the strength properties of the microrods and the granulometric properties of the low-density polyethylene micropellets lead to the following conclusions:

- microrods with the smallest diameter showed the highest tensile strength and a correspondingly high stress at break, whilst at the same time showing the lowest strain - this indicates that the degree of longitudinal tension has a significant effect on strength properties, in particular, tensile stress;

- the dimensions of the micropellets, their lengths and diameters affect their bulk density and their natural repose angle. This means that it is necessary to choose one of the following options: either determin the geometric features of micropellets so that they match the existing design of the feed section of the plasticizing unit (in particular in an extruder), or adjust the design of the feed section of the plasticizing unit to the size of the micropellets that are to be processed. In this way, the process of plasticization will be optimized;

- the largest natural angle of repose was recorded for the smallest micropellets and vice versa. The values of the natural angle of repose can be used in designing the proper dimensions of the hopper of the plasticising unit to ensure the desired polymer flow.

\section{References}

[1] Jin G.B., Wang M.J., Zhao D.Y., Tian H.Q. Jin Y.F., Design and experiments of extrusion die for polypropylene five-lumen micro tube, Journal of Materials Processing Technology, 214, 1, 2014, 50-59.

[2] Wang H., Fu Z.H., Yao D.G., Research of micro profile extrusion, Advanced Materials Research, 87, 1, 2009, 125-129.

[3] Sahli M., Millot C., Roques-Carmes C., Khan Malek C., Barriere T., Gelin J.C., Investigation of polymer inserts as prototyping tooling for micro injection moulding, International Journal of Advanced Manufacturing Technology, 47, 1-4, 2010, 111-123.

[4] Bellantone V., Surace R., Trotta G., Fassi I., Replication capability of micro injection moulding process for polymeric parts manufacturing, International Journal of Advanced Manufacturing Technology, 67, 5-8, 2013, 1407-1421.

[5] Wang B.X., Wang W., Guo L.H., The design of an extrusion head used to produce of micro-interventional catheterIElectromachining \& Mould, 4, 2005, 44-46. 
[6] Jin G.B., Zhao D.Y., Wang M.J., Jin Y.F., Tian H.Q., Zhang J., Study on design and experiments of extrusion die for polypropylene single-lumen micro tubes, Microsystem Technologies, 21, 11, 2015, 2495-2503.

[7] Zhu C.W., Wu D.M., Simulation of extrudate swell for multi-lumen precise medical catheter, Plastics, 37, 6, 2008, 101-105.

[8] Tian H., Zhao D., Wang M., Jin G., Jin Y., Study on extrudate swell of polypropylene in double-lumen micro profile extrusion, Journal of Materials Processing Technology, 225, 2015, 357-368.

[9] Siracusano S., Ciciliato S., Ollandini G., Visalli F., Catheters and Infections, Clinical Management of Complicated Urinary Tract Infection, Intech, 2011, 83-98.

[10] Hayashi K., Takamizawa K., Saito T., Kira K. et al., Elastic properties and strength of a novel small-diameter, compliant polyurethane vascular graft, Journal of Biomedical Materials research Part B: Applied Biomaterials, 23, 1989, 229-244.

[11] Extrand C.W., Moon S.I., Experimental measurement of forces and energies associated with capillary rise in a vertical tube, Journal of Colloid and Interface Science, 407, 2013, 488-492.

[12] Murawski M., The Onset and Progress of Microsurgical Technique, Advances in Clinical and Experimental Medicine, 16, 5, 2007, 701-704.

[13] Callahan T.L., Lear W., Kruzic J.J., Maughan C.B., Mechanical properties of commercially available nylon sutures in the United States, Journal of Biomedical Materials Research Part B: Applied Biomaterials, 2016, DOI: 10.1002/jbm.b33600

[14] Thompson M.R., Xi C., Takacs E., Tate M., Vlachopoulos J., Experiments and Flow Analysis of a Micropelletizing Die, Journal of Polymer Engineering and Science, 44, 7, 2004, 1391-1402.

[15] Ramkumar P.L., Kulkarni D.M., Waigaonkar S.D., Effect of Cycle Time on Mechanical Properties of LLDPE during rotational moulding process, Polymers Research Journal, 8, 1, 2014, 19-33.

[16] Markarian J., Pelletizing: choosing an appropriate method, Plastics, Additives and Compounding, 6, 4, 2004, 22-26.

[17] He C.H., Li X.W., Liu P., Li Y., Bubbfil spinning for fabrication of PVA nanofibers, Thermal Science, 19, 2, 2015, 743-746.

[18] Sikora J.W., Samujło B., Stasiek A., The extrusion of plasticized poly(vinyl chloride) in an extruder with a modified feed zone, Part 1. Extrusion process, Journal of Polymer Engineering, 35, 2, 2015, 191-198.

[19] Dąbrowski A., Adsorption - from theory to practice, Advances in Colloid and Interface Science, 93, 2001, 135-149. 